\title{
Prevalence of pneumococcal serotypes and resistance to antimicrobial agents in patients with meningitis: ten-year analysis
}

\section{Authors}

Jackelline Rodrigues Alvares ${ }^{1}$ Orlando Cesar Mantese ${ }^{2}$ Alan de Paula ${ }^{3}$

Paula Carolina Bejo Wolkers ${ }^{4}$ Viviene Vieira Prado Almeida ${ }^{5}$ Samanta Cristine Grassi Almeida $^{6}$

Maria Luiza Leopoldo Silva Guerra $^{7}$

Maria Cristina de Cunto Brandileone $^{8}$

Master in Health Sciences - Nurse at the Pediatric Intensive Care Unit of the Hospital de Clínicas of Uberlândia $(\mathrm{HCU})$

${ }^{2} \mathrm{PhD}$ - University Professor

Medical School of Uberlândia, MG ${ }^{3}$ Master in Health Sciences. Medical School of the Universidade Federal de Uberlândia

Physician at the Pediatric Intensive Care Unit of the HCU

${ }^{4}$ Master in Health Sciences.

Medical School of the Federal University of Uberlândia - Chief Nurse of the Outpatient Clinics of the HCU

Biochemical Pharmacist.

Specialist in Clinical Microbiology, Universidade de São Paulo; Responsible for the Bacteriology Sector of the Clinical Analysis Laboratory of the $\mathrm{HCU}$ ${ }^{6}$ Master in Sciences by the UNIFESP, São Paulo - Scientific Researcher of the Instituto Adolfo Researcher of the Institu
Lutz, São Paulo, SP ${ }^{7}$ Biochemical Pharmacist. Specialist in Clinical Microbiology - Bacteriologist of the Bacteriolog Sector of the Instituto Adolfo Lutz, São Paulo, SP

${ }^{8} \mathrm{PhD}$ in Sciences by the UNIFESP São Paulo - Coordinator of the Projeto SIREVA and SIREVA II at the Instituto Adolfo Lutz, São Paulo, SP

Submitted: 04/30/2010 Approved: 07/09/2010

Correspondence to: Orlando Cesar Mantese Avenida Pará, 1979. Uberlândia, MG CEP: $38405-320$ Phone: 03432322736 orlando@ufu.br

\begin{abstract}
Objectives: To determine the prevalence of pneumococcal serotypes and antimicrobial susceptibility in patients with meningitis, and to evaluate the implications for vaccine coverage. Methods: Pneumococcal strains obtained from normally sterile fluids from patients admitted with meningitis were isolated at the Hospital de Clinicas of the Universidade Federal de Uberlândia, Minas Gerais State, and sent to the Instituto Adolfo Lutz, city of São Paulo, São Paulo State, for further identification, serotyping, and antimicrobial susceptibility determination. Results: From April 1999 to April 2009, 338 pneumococcal strains were isolated, and 72 obtained from patients with meningitis, were analyzed. Patients' ages varied from one month to 82.2 years (mean of $18.4 \pm 22.9$ years; median of 5.2 years) and $46(63.9 \%)$ patients were male. Strains were isolated from cerebrospinal fluid [66 occasions $(91.7 \%)$ ] and blood [6 occasions $(8.3 \%)$ ]. The most commonly identified serotypes were 14, 19F, 3, 7F, 6A, 6B, 10A, 18C, $23 \mathrm{~F}, 5$, and 34 . Of the 20 [27.8\%] oxacillin-resistant strains, 17 [23.6\%] were resistant to penicillin and nine $[12.5 \%]$ to ceftriaxone, both resistance patterns being more common in children aged two years or less and during the 2005-2009 period. Conclusions: Resistance to penicillin and ceftriaxone was detected in $23.6 \%$ and $12.5 \%$ of the strains, respectively, and predominated in children aged two years or less and during the 2005-2009 period. There were 24 different serotypes of pneumococcus and $79.8 \%$ of the serotypes were represented in the 7-valent conjugated vaccine [PVC7].
\end{abstract}

Keywords: Streptococcus pneumoniae; meningitis; serotyping; pneumococcal vaccines; drug resistance.

[Braz J Infect Dis 2011;15(1):22-27] @Elsevier Editora Ltda.

\section{INTRODUCTION}

Streptococcus pneumoniae is one of the most common agents of pneumonia, meningitis, acute otitis media, and sinusitis in children. ${ }^{1,2}$ It accounts for high morbidity and mortality rates in children under the age of five years and adults over the age of 65 years, ${ }^{2}$ especially in developing countries. ${ }^{3}$ The World Health Organization estimates that from 800 thousands to one million children die every year due to invasive pneumococcal disease, and more than $90 \%$ of the deaths occur in developing countries. ${ }^{4}$ Meningitis is one of the least common manifestations of pneumococcal disease and has the highest rates of morbidity (late neurological sequelae in approximately $40 \%{ }^{5}$ to $58 \%{ }^{6}$ ) and lethality (up to 50\%6) in developing countries. In the USA, prior to the appearance of the Haemophilus influenzae type B (Hib) conjugate vaccine, approximately $95 \%$ of the meningitis cases in children under the age of two years were caused by the bacteria Hib, meningococcus, and pneumococcus. ${ }^{7}$ In Brazil, pneumococcus is the second causative agent of bacterial meningitis, and in the 2001-2006 period, its mean lethality coefficient was 30\%, much higher than those of meningococcus (17.6\%) and Hib (19.8\%). ${ }^{8}$

The clinical course of the pneumococcal disease is influenced by several factors, such as treatment adequacy. The treatment for pneumococcal infections is based on initial antibiotic therapy, which is usually empirical regarding the etiology and in vitro susceptibility to antimicrobial agents. Based on bacterial isolation in culture and antimicrobial susceptibility tests, antibiotic therapy can be then properly adjusted. Penicillin is the drug of choice for many pneumococcal diseases; ${ }^{1}$ however, with the increasing report of penicillinresistant strains since the 1980s, alternative regimens have been proposed. ${ }^{910}$ 
The prevention of invasive disease is mainly based on active immunization. ${ }^{1,2}$ According to the capsular polysaccharide antigen, 91 different serotypes, ${ }^{11,12}$ contained in 46 pneumococcal serogroups, ${ }^{13}$ have been described so far. A 7-valent vaccine (PCV7. Prevenar ${ }^{\circledR}$. Pfizer/Wyeth Pharmaceuticals, Inc.) containing the capsular polysaccharide of serotypes $4,6 \mathrm{~B}, 9 \mathrm{~V}$, $14,18 \mathrm{C}, 19 \mathrm{~F}$, and $23 \mathrm{~F}$, conjugated with a protein carrier, was licensed in the USA in $2000 .{ }^{14}$ The immunogenicity of the polysaccharide is widened by the covalent binding with the protein molecule, particularly in children under the age of two years, and the vaccine protects against nasopharyngeal colonization by the serotypes it contains. ${ }^{14}$ The following two conjugate vaccines have been recently licensed in several countries: the 13-valent (PCV13. Prevenar13 ${ }^{\circledR}$ Pfizer/Wyeth Pharmaceuticals, Inc.) produced with the same protein carrier according to the same conjugation process, which, compared to PCV7, adds the capsular polysaccharide antigen of serotypes 1, 3, 5, 6A, 7F, and $19 \mathrm{~A} ;{ }^{15}$ and the 10 -valent (PCV10. Synflorix ${ }^{\circledR}$. GlaxoSmithKline Biologics AS), which uses different protein carriers and, as compared to PCV7, adds serotypes 1,5 , and $7 \mathrm{~F}^{15}$

Because the antibiotic resistance pattern and pneumococcal serotype prevalence vary in different populations, in different geographical regions and, probably, over time, establishing the profile of the most prevalent serotypes in a certain community and knowing the resistance rates are important to better assess vaccine coverage and to support the choice of initial empiric treatment.

\section{OBJECTIVES}

To document the serotype profile and susceptibility to antimicrobial agents of pneumococcal strains obtained from patients hospitalized with meningitis at the Hospital das Clinicas of the Universidade Federal de Uberlândia (HC-UFU), in addition to assessing the implications for the antipneumococcal vaccine coverage rates.

\section{PATIENTS AND METHODS}

This is a prospective, case-series, laboratory-surveillance study, whose laboratory data of serotyping and in vitro susceptibility to antimicrobial agents of invasive pneumococcal strains were obtained from patients admitted to the HC-UFU. The index case is a pneumococcal strain isolated at the Clinical Analysis Laboratory from clinical specimens (blood or cerebrospinal fluid) of a patient hospitalized with meningitis. Aseptically obtained specimens were properly processed and inoculated in hemoculture bottles (blood sample) or in chocolate-agar and blood-agar plates (other sample types) right after collection and immediately after arrival at the laboratory. Only one pneumococcal isolate per patient per hospitalization was considered in the study. The pneumococcal strains were isolated and identified at the HC-UFU according to internationally described methods and subsequently sent to the Bacteriology Sector of the Instituto Adolfo Lutz (IAL), in the city of São Paulo, for specimen confirmation, serotyping, and determination of in vitro susceptibility to antimicrobial agents. ${ }^{16}$ Pneumococcal strains were lyophilized in $20 \%$ skim milk and properly catalogued. The following two findings characterized a case of meningitis: pneumococcal isolation in the cerebrospinal fluid; or clinical and laboratory findings of meningitis accompanied by the isolation of the agent in blood.

Antimicrobial susceptibility was assessed by using the disk diffusion test with oxacillin ( $1 \mu \mathrm{g})$, tetracycline, ofloxacin, chloramphenicol, erythromycin, sulfamethoxazole-trimethoprim (cotrimoxazole), vancomycin, and clindamycin in MuellerHinton agar plates supplemented with $5 \%$ sheep blood according to the standardized technique. ${ }^{17,18}$ Oxacillin-resistant strains (cleared area $\leq 19 \mathrm{~mm}$ ) underwent subsequent determination of the minimum inhibitory concentration (MIC) of penicillin by using the broth microdilution method and were considered according to the criteria of the Clinical and Laboratory Standards Institute (CLSI), $2008^{19}$ as follows: susceptible [S], MIC $\leq 0.06 \mathrm{mg} / \mathrm{mL}$; and resistant [R], MIC $\geq 0.12 \mathrm{mg} / \mathrm{mL}$, for strains obtained from patients with meningitis. Oxacillin-resistant strains also underwent MIC determination for ceftriaxone and were considered as follows: susceptible, $\mathrm{MIC} \leq 0.5 \mu \mathrm{g} / \mathrm{mL}$; intermediately resistant (IR), MIC $=1 \mu \mathrm{g} / \mathrm{mL}$; and fully resistant (FR), MIC $\geq 2 \mu \mathrm{g} / \mathrm{mL}$ for strains obtained from patients with meningitis. ${ }^{20}$ Oxacillin-susceptible strains (cleared area $>19 \mathrm{~mm}$ ) were considered susceptible to penicillin and did not undergo MIC determination, according to the recommendation of the CLSI, 2007. ${ }^{21}$ The cut-off points defined for penicillin $^{19}$ and ceftriaxone ${ }^{20}$ were applied to the results (MIC) obtained during the study period, and maintained in a database.

Serotyping was performed by use of the Neufeld Quellung reaction, a technique previously described ${ }^{22}$ by using polyclonal antisera. ${ }^{11}$

Data from April 1999 to April 2009 were obtained and the results were submitted to statistical analysis. The results were analyzed in two time periods, considering the reports on the increase in resistance rates over time. ${ }^{23,24}$ Only two periods of time were chosen because of the limited size of the sample.

For comparing the proportions of the pattern of antimicrobial susceptibility in the different time periods and age ranges, the chi-square test $\left(\chi^{2}\right)$ was used. Tests of normality and homogeneity of the samples were used whenever necessary. The level for rejecting the null hypothesis was fixed as 5\% $(\mathrm{P}<0.05)$.

The study was approved by the Committee on Ethics in Research of the Universidade Federal de Uberlândia (CEP/UFU, protocol 210/08).

\section{RESULTS}

From April 1999 to April 2009, 72 pneumococcal strains obtained from patients with meningitis were sent to the IAL and assessed. Forty-six (63.9\%) strains originated from males, and age ranged from one month to 82.2 years (mean, 18.4 
\pm 22.9 years; median, 5.2 years; 25 th percentile, 5.2 months; and 75 th percentile, 36 years). The number of isolations per age bracket was 33 in children up to 24 months, two in children from 25 to 60 months, nine in children from 61 months to 12 years, 23 in patients from over 12 to 60 years, and five in patients older than 60 years. The number of samples studied per year obtained from 1999 to 2009 was $6,11,8,7,7,8$, $5,9,6,3$, and 2 , respectively. The sources of collection were cerebrospinal fluid in 66 samples $(91.7 \%)$ and blood in six samples $(8.3 \%)$. Overall lethality rate of $25 \%$ (18/72) was lower than that of children aged two years or less $(36.4 \%)$ and that of adults over the age of 60 years $(80 \%)$.
Twenty-four different serotypes were identified and the most common are shown in Table 1, according to the different age brackets.

Twenty $(27.8 \%)$ oxacillin-resistant strains were detected. According to the CLSI criteria, 2008, ${ }^{19} 17$ (23.6\%) subsequently confirmed penicillin resistance, which was limited to serotypes 14 (11 strains), 19F, 23F (two strains each), 6B, and 19A (one strain each). Resistance predominated in children aged up to two years (Table 2; $\mathrm{P}=0.004$ ) and in the 2005-2009 period as compared to the 1999-2004 period (Table 2; $\mathrm{P}=0.003$ ). Ceftriaxone resistance was detected in nine of the 17 penicillin-resistant strains, at a rate

Table 1. Distribution of the pneumococcal serotypes according to the age bracket of patients hospitalized with meningitis from 1999 to 2009

\begin{tabular}{|c|c|c|c|c|c|c|}
\hline Serotypes & $\leq 60 \mathrm{~m}$ & $\%$ & $>60 \mathrm{~m}$ & $\%$ & Total & $\%$ \\
\hline 14 & 16 & 45.8 & 3 & 8.1 & 19 & 26.3 \\
\hline $19 \mathrm{~F}$ & 2 & 5.7 & 5 & 13.5 & 7 & 9.7 \\
\hline 3 & 1 & 2.9 & 4 & 10.8 & 5 & 6.9 \\
\hline $7 F$ & 2 & 5.7 & 3 & 8.1 & 5 & 6.9 \\
\hline $6^{\mathrm{a}}$ & 3 & 8.5 & 1 & 2.7 & 4 & 5.6 \\
\hline $6 B$ & 3 & 8.5 & 1 & 2.7 & 4 & 5.6 \\
\hline $10^{\mathrm{a}}$ & 1 & 2.9 & 2 & 5.4 & 3 & 4.2 \\
\hline $18 \mathrm{C}$ & 3 & 8.5 & 0 & 0.0 & 3 & 4.2 \\
\hline $23 \mathrm{~F}$ & 1 & 2.9 & 2 & 5.4 & 3 & 4.2 \\
\hline 5 & 1 & 2.9 & 1 & 2.7 & 2 & 2.8 \\
\hline 34 & 0 & 0 & 2 & 5.4 & 2 & 2.8 \\
\hline Others $^{1}$ & 2 & 5.7 & 13 & 35.2 & 15 & 20.8 \\
\hline Total & 35 & 100.0 & 37 & 100.0 & 72 & 100.0 \\
\hline
\end{tabular}

${ }^{1}$ Others: $\leq 60$ months - serotypes 1 and $18 \mathrm{~B}$ (one of each);

$>60$ months - serotypes $4,7 \mathrm{C}, 9 \mathrm{~N}, 10 \mathrm{~F}, 11 \mathrm{~A}, 18 \mathrm{~A}$,

19A, 20, 23A, 28A, non-classifiable (one of each), serogroup H (two strains).

Table 2. Distribution of pneumococcal strains isolated from patients with meningitis, according to susceptibility to penicillin, age bracket, and isolation period

\begin{tabular}{|c|c|c|c|c|c|}
\hline \multirow{3}{*}{$\begin{array}{l}\text { Age (months) } \\
\text { Period (year) }\end{array}$} & \multicolumn{4}{|c|}{ Susceptibility to penicillin } & \multirow[t]{3}{*}{ Total } \\
\hline & \multicolumn{2}{|c|}{ Susceptible* } & \multicolumn{2}{|c|}{ Resistant ${ }^{* *}$} & \\
\hline & $\leq 24$ & $>24$ & $\leq 24$ & $>24$ & \\
\hline 1999-2004 & 17 & 24 & 4 & 2 & 47 \\
\hline 2005-2009 & 3 & 11 & 9 & 2 & 25 \\
\hline Subtotal & 20 & 35 & 13 & 4 & 72 \\
\hline Total & & 55 & & 17 & 72 \\
\hline
\end{tabular}

*Presumed susceptibility by use of the oxacillin disk diffusion test.

$* *$ According to the CLSI criterion, 2008. 
of $12.5 \%(9 / 72), 6.9 \%(5 / 72)$ being intermediate resistance, and 5.6\% (4/72) full resistance. Also for ceftriaxone, resistance predominated in children aged up to two years (Table 3; $\mathrm{P}=0.039$ ) and in the 2005-2009 period as compared to the 1999-2004 period (Table 3; $\mathrm{P}=0.000$ ). The maximum penicillin and ceftriaxone MIC were $4 \mu \mathrm{g} / \mathrm{mL}$ and $2 \mu \mathrm{g} / \mathrm{mL}$, respectively. No resistance to chloramphenicol, ofloxacin, rifampicin or vancomycin was observed.

\section{DISCUSSION}

Despite the small size of the population studied, similarities with the results of other national ${ }^{25-32}$ and Latin-Ameri$\operatorname{can}^{25-28}$ surveys could be identified. The profile of the most frequently found serotypes in developing countries has been confirmed, 14, 19F, 3, 7F, 6A/6B, 10A, 18C, 23F, 5, and 1, with an emphasis on the high prevalence of serotypes 1 and 5 , commonly found in Latin America. ${ }^{13,26,27,28}$

The SIREVA Project collected 2,584 invasive pneumococcal strains from different Brazilian regions during a three-year period: $2006,{ }^{26} 2007,{ }^{27}$ and $2008{ }^{28}$ The analysis of the most frequently found serotypes in children with meningitis up to the age of five years indicated a $76.9 \%$ coverage rate of the PCV7 vaccine, including serotype $6 \mathrm{~A}$. According to data in Table 1 , the vaccine coverage in the population under the age of five years studied should be $71.3 \%$ (79.8\% when including serotype $6 \mathrm{~A})$ and would not include serotypes 1, 3, and 5, also isolated. Nevertheless, serotypes 6B, 14, 19F, and 23F, among which penicillin-resistant strains can be found, would be covered (100\% vaccine coverage). The PCV10 vaccine coverage in the population here studied would be $82.8 \%$ (91.3\% with serotype $6 \mathrm{~A})$, and the PCV13 vaccine coverage would increase to $94.2 \%$.

The comparison of the proportions according to age bracket (Table 1) suggests a predominance of serotypes $14,6 \mathrm{~A}, 6 \mathrm{~B}$, and $18 \mathrm{C}$ in children aged up to five years and of serotype 3 in patients over that age, a fact also reported in other studies. ${ }^{31,32}$ Serotype 3, associated with severe forms of pneumonia in adults, ${ }^{13,29}$ is also an important cause of invasive disease in newborns and infants, justifying its inclusion in a vaccine to protect children under the age of two years. ${ }^{13}$ In our survey, serotype 3 is one of the most commonly found in patients with meningitis, and also found in children under the age of two years. The high frequency of serotypes $14,6 \mathrm{~A}$, and $6 \mathrm{~B}$ in invasive disease, especially in infants with meningitis, has already been reported in national ${ }^{26-32}$ and Latin-American ${ }^{26-28}$ studies.

Although some serotypes have been associated with a particular disease, there is no exclusivity and different serotypes can cause different diseases. ${ }^{13}$ Because they are non-completely dependent variables, the correlation of the serotype profile with the disease type can be influenced by other factors, such as temporality and age. ${ }^{13}$ However, serotype $18 \mathrm{C}$ has been more commonly associated with meningitis ${ }^{13}$ and serotype 19A with pneumonia. ${ }^{29}$ In this study, serotype $18 \mathrm{C}$ was detected in children under the age of five years (8.5\%) and serotype 19A, in only one patient over that age. Despite its low frequency in Brazill ${ }^{25-29}$ and other LatinAmerican countries, serotype $19 \mathrm{~A}$ is associated with penicillin resistance $\mathrm{e}^{13,23,30-32}$ and is currently an important emerging serotype in the USA, after the release of the heptavalent conjugate vaccine for universal use. ${ }^{7,13}$

In this study, the penicillin-resistance rate was $23.6 \%$ (17/72 strains) when all age brackets were considered, and $39.4 \%$ for ages up to two years (Table 2). Those figures are greater than the $15 \%$ found when considering the different ages and nosologies, and greater than the $29.6 \%$ found when considering children up to two years, in that same population in 2003. ${ }^{33}$ Those figures are close to those found in patients hospitalized with meningitis at other places: $20.3 \%$ at different ages and $24.3 \%$ in children aged up to five years at the Brazilian Federal District; ${ }^{32} 36.4 \%$ in patients aged from one month to 15 years in the city of São Paulo; ${ }^{30}$ and, in the city of Salvador, overall rate of $15.2 \%$ and predominance in children under the age of five years (35\%) as compared with older children $(9 \%) .{ }^{31}$

Table 3. Distribution of pneumococcal strains isolated from patients with meningitis according to susceptibility to ceftriaxone, age bracket, and isolation period

\begin{tabular}{|c|c|c|c|c|c|}
\hline \multirow{3}{*}{$\begin{array}{l}\text { Age (months) } \\
\text { Period (year) }\end{array}$} & \multicolumn{4}{|c|}{ Susceptibility to ceftriaxone* } & \multirow[t]{3}{*}{ Total } \\
\hline & \multicolumn{2}{|c|}{ Susceptible } & \multicolumn{2}{|c|}{ Resistant } & \\
\hline & $\leq 24$ & $>24$ & $\leq 24$ & $>24$ & \\
\hline 1999-2004 & 20 & 26 & 1 & 0 & 47 \\
\hline $2005-2009$ & 6 & 11 & 6 & 2 & 25 \\
\hline Subtotal & 26 & 37 & 7 & 2 & 72 \\
\hline Total & & 63 & & 9 & 72 \\
\hline
\end{tabular}

*According to the NCCLS criterion, 2002. 
Significant increases in the penicillin-resistance rates of invasive pneumococcal strains have been reported in Brazil, from $10.2 \%$ in 1993 to $27.9 \%$ in $2004 .{ }^{23}$ Those values can be compared with those of recently published Brazilian surveys $^{27,28}$ that apply the new categorization criteria for penicillin. ${ }^{19}$ Analyzing the invasive pneumococcal strains obtained from patients with meningitis during the years $2007^{27}$ and $2008,{ }^{28}$ the penicillin resistance rates for different ages was $31.5 \%$ and for children up to two years of age $50.4 \% .^{27,28}$

Penicillin resistance has been restricted to serotypes 14 (11 strains), 19F, 23F (two strains each), 6B, and 19A (one of each), classically associated with drug resistance. ${ }^{13}$ Those are the socalled "pediatric serotypes", responsible for a large number of infectious episodes in children. The age-dependent intrinsic characteristics of immunogenicity and the extensive exposure to antimicrobial agents have contributed, respectively, to the predominance among younger children and the development of penicillin resistance. ${ }^{13,23}$ This study could confirm the increase in the proportion of penicillin-resistant strains related to age $(39.4 \%$ up to two years versus $10.3 \%$ above that age; Table 2; $\mathrm{P}=0.004$ ) and to the time period (from 1999 to 2005, $12.8 \%$; and from 2005 to $2009,44 \%$; Table $2 ; \mathrm{P}=0.003)$. The tendency towards an increase in penicillin resistance in Brazil over time has already been demonstrated in a Brazilian study ${ }^{23}$ and has been associated with the emergence and dissemination of two international pneumococcal clones denominated Spain ${ }^{9 \mathrm{~V}}-3$ and Tennessee. ${ }^{14-18}$ Theses clones, which express the capsule of serotype 14 and are characterized by drug resistance, have predominated in the southern and southeastern regions of Brazil since 1998. Of the 17 isolated penicillinresistant clones detected in the present study, 11 (64.7\%) are serotype 14, and, thus, one can speculate that, at least partially, the increase in the proportion of resistant strains results from dissemination of the referred clones in that community.

The nine ceftriaxone-resistant pneumococcal strains (five IR strains and four FR strains) found in this study account for a $12.5 \%$ resistance rate, close to that reported in Brazilian laboratory surveillance studies ${ }^{26-28}$ when using the current cut-off points for ceftriaxone. ${ }^{20}$ Based on the invasive strains obtained from patients with meningitis in $2006,{ }^{26} 2007,{ }^{27}$ and $2008,{ }^{28}$ a $11.9 \%$ rate of ceftriaxone resistance was detected, 9.1\% being IR and 2.8\% FR. Considering only children aged up to five years, admitted with invasive disease (23.2\% with meningitis) from 1999 to 2009 , a $5.6 \%$ ceftriaxone-resistance rate was found in the same population assessed in this study. ${ }^{34}$

The documented resistance rates for both penicillin and ceftriaxone vary depending on factors, such as geographical location, sample size, time and duration of the assessment, patient's age, and nosology. Usually, resistance tends to predominate in children, ${ }^{23,31-33}$ especially in those with meningitis, ${ }^{23,34}$ with increasing frequency $y^{23,32,34}$ and intensity ${ }^{23}$ over time in the communities not undergoing universal vaccination.
The most appropriate methodology to estimate pneumococcal disease rates in a community consists in clinical population surveillance, based on the laboratory identification of the agent. ${ }^{7}$ That requires up-to-date data of population census and consistent techniques of accurate pneumococcal isolation and identification. This study used laboratory surveillance of invasive hospital-based strains, which is a limitation to conclusions. Epidemiological data should be carefully extrapolated, particularly for those diseases diagnosed and treated outside the hospital setting.

Local or regional pattern of drug susceptibility should be monitored to support the choice of the best empiric therapeutic regimen for invasive pneumococcal diseases. For the specific directed treatment, the antibiotic choice is influenced by the laboratory categorization (susceptible or resistant, according to the MIC) and every effort should be made in the search for the causative agent and determination of its susceptibility to antimicrobial agents.

Finally, the greatest impact on morbidity and mortality of pneumococcal meningitis results from its prevention through the universal use of the conjugate vaccine in the target population, similarly to what happened with the Hib and pneumococcal infection in the USA. ${ }^{7}$ The decision of the Brazilian Ministry of Health to include the pneumococcal conjugate vaccine in the National Immunization Calendar of all children aged up to two years from this year on is of paramount importance.

\section{REFERENCES}

1. American Academy of Pediatrics. Pneumococcal infections. In: RED BOOK - Report of the Committee on Infectious Diseases. 27ed., Illinois, Elk Grove Village. 2009. pp. 524-35.

2. Lynch III JP, Zhanel GG. Streptococcus pneumonia: Epidemiology, Risk Factors, and Strategies for Prevention. Semin Respir Crit Care Med. 2009; 30(2):189-209.

3. Quadros CA. From global to regional: The importance of pneumococcal disease in Latin America. Vaccine 2009; 27(Suppl):29-32.

4. World Health Organization (WHO). Pneumococcal conjugate vaccine for childhood immunization. Who position paper. Wkly Epidemiol Rec. 2007; 82:93-104.

5. Saha SK, Khan NZ, Ahmed ASMNV et al. for The Meningitis Study Group Bangladesh. Neurodevelopmental Sequelae in Pneumococcal Meningitis Cases in Bangladesh: a Comprehensive Follow-up Study. Clin Infect Dis. 2009; 48(S5):S90-96.

6. Goetghebuer T, West TE, Wermenbol V et al. Outcome of meningitis caused by Streptococcus pneumoniae and Haemophilus influenzae type b in children in The Gambia. Trop Med Int Health 2000; 5(3):207-13.

7. Hsu HE, Shutt KA, Moore MR et al. Effect of Pneumococcal Conjugate Vaccine on Pneumococcal Meningitis. N Engl J Med. 2009; 360:244-256.

8. Ministério da Saúde. Secretaria de Vigilância em Saúde. Boletim Epidemiológico. Disponível em http://portal.saude.gov. br/portal/saude/profissional. Accessed on 01/13/2010. 
9. Okeke IN, Laxminaraian R, Bhutta ZA et al. Antimicrobial resistance in developing countries. Part I: recent trends and current status. Lancet Infect Dis. 2005; 5:481-93.

10. Tunkel AR, Hartman BJ, Kaplan SL et al. Practice Guidelines for the Management of Bacterial Meningitis. Clin Infect Dis. 2004; 39:1267-1284.

11. Henrichsen J. The pneumococcal typing system and pneumococcal surveillance. J Infect Dis. 1979; 1(suppl): S31-7.

12. Park IH, Pritchard DG, Cartee R et al. Discovery of a new capsular serotype (6C) within serogroup 6 of Streptococcus pneumonia. J Clin Microbiol. 2007; 45(4):1225-1233.

13. Hausdorff WP, Feikin DL, Klugman KP. Epidemiological differences among pneumococcal serotypes. Lancet Infect Dis. 2005; 5:83-93.

14. CDC. Progress in Introdution of Pneumococcal Conjugate Vaccine-Worldwide, 2000-2008. MMWR 2008; 57(42):1148-1151.

15. Dagan R, Frash C. Clinical Characteristics of a Novel 10-Valent Pneumococcal Non-Typeable Haemophilus influenza Protein D Conjugate Vaccine Candidate (PHiD-CV). Introduction. Pediatr Infect Dis J. 2009; 28(4):S63-65.

16. Brandileone MCC, Vieira VSD, Casagrande ST et al. Prevalence of serotypes and antimicrobial resistance of Streptococcus pneumoniae strains isolated from Brazilian children with invasive infections. Microbial Drug Resistance 1997; 3:141-6.

17. National Committee for Clinical Laboratory Standards. Performance standards for antimicrobial disk susceptibility tests: approved standard. NCCLS Publication M2-A5. Villanova, PA: National Committee for Clinical Laboratory Standards, 1997.

18. Clinical and Laboratory Standards Institute/NCCLS. Performance Standards for Antimicrobial Susceptibility Testing; Fifteenth Informational Supplement. CLSI/NCCLS document M100-S15. Wayne, PA, USA. Clinical and Laboratory Standards Institute, 2005.

19. Clinical and Laboratory Standards Institute. Performance Standards for Antimicrobial Susceptibility Testing; Eighteenth Informational Supplement. CLSI Publication M100-S18, Vol. 28, No. 1. Wayne, PA, USA. Clinical and Laboratory Standards Institute, 2008.

20. National Committee for Clinical Laboratory Standards. Supplemental Tables. Performance Standards for Antimicrobial Susceptibility Testing; Twelfth Informational Supplement. NCCLS Publication M100-S12, Vol. 22, No. 1. M2-A7 and M7A5.Villanova, PA: National Committee for Clinical Laboratory Standards, 2002.

21. Clinical and Laboratory Standards Institute. Performance Standards for Antimicrobial Susceptibility Testing; Sixteenth Informational Supplement. CLSI Publication M100-S17. Wayne, PA, USA. Clinical and Laboratory Standards Institute, 2007.

22. Sorensen UBS. Typing pneumococcal using 12 pooled antisera. J Clin Microbiol. 1993; 31:2097-3000.
23. Brandileone MCC, Casagrande ST, Guerra MLLS et al. Increase in numbers of $\beta$-lactam-resistant invasive Streptococcus pneumoniae in Brazil and the impact of conjugate vaccine coverage. J Med Microbiol. 2006; 55:567-574.

24. Garcia S, Levine OS, Cherian T et al. and the Working Group Members. Pneumococcal disease and vaccination in the Americas: an agenda for accelerated vaccine introduction. Rv Panam Salud Publica/Pan Am J Public Health 2006; 19(5):340-348.

25. Organización Panamericana de la Salud. Informe Regional de SIREVA II: datos por país y por grupo de edad sobre las características de los aislamientos de Streptococcus pneumoniae, Haemophilus influenzae y Neisseria meningitidis em processos invasores, 2000-2005. Documentos Técnicos. Tecnologias Esenciales de Salud. THS/EV-2007/002. Washington, D.C.: OPS, 2007.

26. Organización Panamericana de la Salud. Informe Regional de SIREVA II, 2006: datos por país y por grupo de edad sobre las características de los aislamientos de Streptococcus pneumoniae, Haemophilus influenzae y Neisseria meningitidis em processos invasores. Documentos Técnicos. Tecnologias Esenciales de Salud. THS/EV-2008/001. Washington, D.C.: OPS, 2008.

27. Organización Panamericana de la Salud. Informe Regional de SIREVA II, 2007: datos por país y por grupo de edad sobre las características de los aislamientos de Streptococcus pneumoniae, Haemophilus influenzae y Neisseria meningitidis em processos invasores. Documentos Técnicos. Tecnologias Esenciales de Salud. THS/EV-2008/003. Washington, D.C.: OPS, 2008.

28. Organización Panamericana de la Salud. Informe Regional de SIREVA II, 2008: datos por país y por grupo de edad sobre las características de los aislamientos de Streptococcus pneumoniae, Haemophilus influenzae y Neisseria meningitidis em processos invasores. Documentos Técnicos. Tecnologias Esenciales de Salud. THS/EV-2008/003. Washington, D.C.: OPS, 2009.

29. Brandileone MCC, Andrade ALSS, Di Fabio JL et al. Appropriateness of a Pneumococcal Conjugate Vaccine in Brazil: Potencial Impact of Age and Clinical Diagnosis, with Emphasis on Meningitis. J Infect Dis. 2003; 187:1206-1212.

30. Berezin EN, Carvalho LH, Lopes CR et al. Meningite pneumocócica na infância: características clínicas, sorotipos mais prevalentes e prognóstico. J Pediatr. (Rio J) 2002; 78(1):19-23.

31. Reis JN, Cordeiro SM, Coppola SJ et al. Population-Based Survey of Antimicrobial Susceptibility and Serotype Distribution of Streptococcus pneumoniae from Meningitis Patients in Salvador, Brazil. J Clin Microbiol. 2002; 40(1):275-277.

32. Vieira AC, Gomes MC, Rolo Filho M et al. Streptococcus pneumoniae: estudo de cepas isoladas de liquor. J Pediatr. (Rio J) 2007; 83(1):71-78.

33. Mantese OC, Paula A, Moraes AB et al. Prevalência de Sorotipos e Resistência Antimicrobiana de Cepas Invasivas do Streptococcus pneumoniae. J Pediatria (Rio Janeiro) 2003; 79(6):537-42.

34. Mantese OC, Paula A, Almeida VVP et al. Prevalência de sorotipos e resistência antimicrobiana de cepas invasivas do pneumococo em crianças: análise de 9 anos. J Pediatr. (Rio J) 2009; 85(6):495-502. 